\title{
Proceeding
}

Supplementary Issue: Winter Conferences of Sports Science. Costa Blanca Sports Science Events, 25-26 January 2019.

Alicante, Spain

\section{Transition period: Pilot study on performance reduction of ability to jump in volleyball}

\author{
DANTE FORTE $1 \triangleleft$, ANDREA CECILIANI ${ }^{2}$, RICCARDO IZZO ${ }^{3}$, GAETANO ALTAVILLA ${ }^{4}$ \\ ${ }^{1}$ University of Salerno, Italy \\ 2University of Bologna, Italy \\ ${ }^{3}$ University Carlo Bo of Urbino, Italy \\ ${ }^{4}$ University of Split, Croatia
}

\begin{abstract}
As previously introduced in the preliminary study (Forte \& Altavilla, 2018) we want to estimate the reduction in performance in the transition period, the purpose of this work is to expand the sample of data on the ability to jump. The method is experimental and the study was conducted on the same sample of 22 female athletes divided into two experimental groups, the first composed of athletes aged 12-16 years and the second on athletes aged 18-25 years. In all subjects the following parameters were assessed: height with a stretched arm and height with two extended arms. The elevation and coordination skills were evaluated with the Abalakov test using the technical gesture of the attack and the wall. Other data were obtained by evaluating the results obtained from the difference between the measurement of the attack and the height with an extended arm, and between that of the wall and the height with two extended arms. The test results showed significant reductions in ability to jump after the transition period. Key words: Abalakov test; Transition period; Performance; Motor skills.
\end{abstract}

\section{Cite this article as:}

Forte, D., Ceciliani, A., Izzo, R., \& Altavilla, G. (2019). Transition period: Pilot study on performance reduction of ability to jump in volleyball. Journal of Human Sport and Exercise, 14(2proc), S221-S227. doi:https://doi.org/10.14198/ihse.2019.14.Proc2.09

Corresponding author. University of Salerno, Italy.

E-mail: danteforte@outlook.it

Supplementary Issue: Winter Conferences of Sports Science. Costa Blanca Sports Science Events, 25-26 January 2019. Alicante, Spain.

JOURNAL OF HUMAN SPORT \& EXERCISE ISSN 1988-5202

(c) Faculty of Education. University of Alicante.

doi:10.14198/jhse.2019.14.Proc2.09 


\section{INTRODUCTION}

Volleyball is classified as an activity with alternating aerobic and anaerobic (Tiziana et al., 2017) engagement with a high percentage of body muscle mass and district demands for high forces. The activity is based on the alternation, more or less regular, random or chosen on the basis of technical-tactical needs and the competitive moment, of submaximum (aerobic), maximum (anaerobic) and rest phases. The limited dimensions of the field determine a performance characterized (Di Tore et al., 2018, D'elia, F et al 2018, Raiola 2017, Raiola, Di Tore, 2017, Di Tore, Gaetano R, 2012) by technical gestures (jumps, attack shots, etc..) at high speeds and intensities and by shots, sometimes starting from very low positions, over distances from 3 to 12 meters.

The players perform between 70 and 150 jumps during the competition, including attack jumps, wall jumps and serve (By Lobietti). In order to completely define the physiological characteristics of a sport, it is necessary to evaluate also the basic functional qualities of the practicing athletes. Therefore, the purpose of this study is to enlarge the sample of data obtained in the preliminary study (Forte, Altavilla 2018) to estimate the reduction in performance(Gaetano A. 2016) after the transition period (Raiola, D'Isanto, 2016). From the beginning of the 2017/2018 season, anthropometric samples have been taken and various types of performance tests have been given to the athletes, following the canons of the scientific study (Raiola et al., 2018, Raiola, 2014, Raiola Di Tore, 2012abc, Raiola, 2012, 2013).

\section{METHODS}

\section{Subjects}

The survey was carried out on a sample of 22 female volleyball players who have practiced this discipline for at least 5 years of competitive activity and participate in an average of 3 training sessions per week. The age of the players differs significantly from one group to another, respectively in age of development (12-16 years) and not (18-25 years) evaluating: anthropometric measurements (reach to 1 hand-reach to 2 hands) explosive force of the lower limbs (jump from standing and chase).

For each of the tests, precise criteria for measurement and performance are indicated which, without falling into the trap, must limit the personal interpretations of the technicians (Cirillo et al., 2016).

\section{Elevation test}

For this test, a graduated scale in centimetres has been set up on a wall. During the test, the trainer must be in an optimal position at the top near the meter. Gypsum powder was used to help determine the height reached. If the tests are not carried out periodically, it is advisable to have the athletes make some preliminary attempts and mark the ideal line of detachment on the floor.

The anthropometric parameters were initially measured with regard to the maximum point reached with feet on the ground and an arm stretched to the maximum (Height with a stretched arm, HSA1) and two arms stretched to the maximum (Height with two stretched arms, HSA2).

Subsequently, the following tests were carried out:

1. Spike Jump (SJ): the athlete with a chase at will but with two-legged detachment tries to touch as high as possible with the dominant hand (unit of measure $1 \mathrm{~cm}$ ) 
2. Block Jump (BJ): standing still under the meter and without counter movement, the height reached is measured - only a small difference between the height reached between the two hands can be tolerated (unit of measurement $1 \mathrm{~cm}$ ).

They were derived from the data collected also:

- elevation from standstill (SE): difference in cm between the block jump and the reach 2 hands;

- elevation with run-up (EWRU): difference in $\mathrm{cm}$ between the value of the spike jump and the reach 1 hand.

Each test is characterized by the execution of three jumps: for the statistical survey is considered the best result. In this study the Abalakov test was used to measure and evaluate the elevation in a specific way, using the technical action of the attack to the net and the action of the wall. Each player simulates the attack action with a run-up phase and the wall action starting from a static position. Other data have been obtained by evaluating the results obtained from the difference between the measure of the attack action with a runup step and the maximum measure reached by extending the dominant arm, and again, between the technical action of the wall from a standstill and the maximum measure reached by completely extending the upper limbs. In this way it is possible to calculate the elevations obtained by the various players by jumping with and without running.

\section{Statistics analysis}

Data on the anthropometric characteristics and results of the Abalakov test are presented as average and standard deviation (SD) (D'isanto, T et al ,2018, Altavilla et al 2018, Altavilla et al 2017). The comparison of the anthropometric data and jumping ability was done between two groups of different ages.

\section{RESULTS}

\section{Table $1 \quad$ Anthropometric data Table 2 Anthropometric data}

\begin{tabular}{|c|c|c|c|c|c|}
\hline Group $A \quad(n=12)$ & $M$ & $\overline{D S}$ & Group B $(n=10)$ & M & $\overline{S D}$ \\
\hline Age (year) & 14,8 & 3,7 & Age (year) & 21,6 & 3,9 \\
\hline Height $(\mathrm{cm})$ & 160,1 & 5,1 & Height (cm) & 162,2 & 4,2 \\
\hline Weight (Kg) & 57,8 & 9,1 & Weight (Kg) & 56,9 & 4,3 \\
\hline HSA1 (cm) & 209,6 & 7,29 & HSA1 (cm) & 210,1 & 6,42 \\
\hline HSA2 (cm) & 206,6 & 6,84 & HSA2 (cm) & 207,4 & 6,08 \\
\hline
\end{tabular}


Table 3 Test Spike jump (cm)

\begin{tabular}{|c|c|c|c|c|c|}
\hline \multicolumn{3}{|c|}{ Group A } & \multicolumn{3}{|c|}{ Group B } \\
\hline & June $S$ & September & & June $\mathrm{Se}$ & September \\
\hline 1 & 243 & 250 & 1 & 238 & 245 \\
\hline 2 & 248 & 246 & 2 & 251 & 246 \\
\hline 3 & 235 & 233 & 3 & 252 & 248 \\
\hline 4 & 255 & 251 & 4 & 256 & 250 \\
\hline 5 & 245 & 251 & 5 & 248 & 243 \\
\hline 6 & 248 & 245 & 6 & 250 & 245 \\
\hline 7 & 230 & 220 & 7 & 265 & 257 \\
\hline 8 & 240 & 245 & 8 & 250 & 240 \\
\hline 9 & 258 & 257 & 9 & 228 & 220 \\
\hline 10 & 233 & 228 & 10 & 248 & 245 \\
\hline 11 & 230 & 227 & & & \\
\hline 12 & 245 & 241 & & & \\
\hline Aver & ge 242,5 & 241,17 & Aver & ge 235 & 233,75 \\
\hline Medi & an 244 & 245 & Medi & n 235 & 236 \\
\hline $\max$ & 258 & 257 & $\max$ & 251 & 246 \\
\hline $\min$ & 230 & 220 & $\min$ & 220 & 215 \\
\hline sd & 9,22 & 11,54 & sd & 10,02 & 10,91 \\
\hline
\end{tabular}

\section{Table 4}

\begin{tabular}{|c|c|c|}
\hline \multicolumn{2}{|c|}{ Group A } & September \\
\hline 1 & 235 & 241 \\
\hline 2 & 242 & 240 \\
\hline 3 & 235 & 230 \\
\hline 4 & 250 & 245 \\
\hline 5 & 231 & 245 \\
\hline 6 & 240 & 237 \\
\hline 7 & 220 & 215 \\
\hline 8 & 230 & 231 \\
\hline 9 & 251 & 246 \\
\hline 10 & 228 & 225 \\
\hline 11 & 220 & 215 \\
\hline 12 & 238 & 235 \\
\hline
\end{tabular}

Average 248,6 243,9

Median $250 \quad 245$

$\max \quad 265 \quad 257$

$\min 228 \quad 220$

sd $\quad 9,90 \quad 9,55$
Test Block Jump (cm)

\begin{tabular}{|c|c|c|}
\hline \multicolumn{3}{|c|}{ Group B } \\
\hline 1 & $\begin{array}{l}\text { June } \\
230\end{array}$ & $\begin{array}{l}\text { September } \\
235\end{array}$ \\
\hline 2 & 245 & 231 \\
\hline 3 & 245 & 243 \\
\hline 4 & 245 & 242 \\
\hline 5 & 237 & 233 \\
\hline 6 & 238 & 232 \\
\hline 7 & 251 & 246 \\
\hline 8 & 238 & 233 \\
\hline 9 & 220 & 215 \\
\hline 10 & 240 & 237 \\
\hline
\end{tabular}

Average 238,9 234,7

Median $239 \quad 234$

$\max 251 \quad 246$

$\min 220 \quad 215$

sd $\quad 8,82 \quad 8,63$ 


\section{Table 5 elevation data (average + SD) Group A}

\section{June}

$\overline{\text { SE }(\mathrm{cm}) \quad 28,33 \pm 8,25}$

EWRU (cm) 32,83 $\pm 6,75$

Gruppo B
September

SE (cm) $27,08 \pm 6,76$

EWRU (cm) $31,50 \pm 7,32$

\section{September}

\begin{tabular}{lr}
\hline SE $(\mathrm{cm})$ & $27,3 \pm 7,73$ \\
EWRU $(\mathrm{cm})$ & $33,8 \pm 7,86$
\end{tabular}

\section{DISCUSSION}

From the statistical analysis of the tests on both group $A$ and group $B$, we can say that the transition period has led to a reduction in performance in all the capacities analysed. Almost all the girls worsened during the transition period in the strength of the lower limbs. In particular, only in some cases we have seen that group A compared to group B has better values, it should be noted that with regard to the height of the jump and the elevation to the wall are power tests very closely related to the technique of execution, this implies that the two groups are homogeneous from the physical point of view while the difference is found in the technique and coordination skills.

Tables 1 and 2 show the mean and standard deviation of the anthropometric data. In Tables 3 and 4 the results of the Abalakov test show significant variations. A reduction in performance was found in both Spike Jump and Block Jump tests. Table 5 shows the mean values and standard deviation of the elevation from standstill and with run-up.

The specific objective of an athletic training program is to create an athlete, equipped with the muscle and joint groups necessary to withstand the short and medium-term stresses that the practice of volleyball imposes during a sporting career. Before deciding whether to devote and how much time to physical preparation is important to know the characteristics of the players at their maximum performance and at the beginning of the preparation knowing the degree of reduction of performance occurred in the transition period, you must also consider some factors such as: the age of the athletes, the amount of weekly training hours and the organization of the championship. It often happens to find teams where the physical and athletic preparation is entrusted to improvisation, to the limited experiences made by the coach or even is very secondary and poorly considered. The preparation is greatly affected by these shortcomings: are strongly limited the potential of the subjects, prejudiced the sporting maturation of a young man, creating the conditions for consequent possible trauma.

In recent years, the collective awareness of the important role of physical preparation for the activity and development of an athlete has improved considerably; however, in all sports specialties, at a lower competitive level, the contents of this preparation are often lacking. If this way of preparation is contraindicated at all levels, it is even more so at the juvenile level. For young people, preparing in this way can mean compromising their training, limiting their sporting growth. Physical and athletic improvement is achieved by perfecting the motor qualities through the improvement of the overall physical efficiency of the 
person. In all sports, in order to achieve the best performance, a close synergy between athletic work and technical work is of fundamental importance, with a physical preparation carried out on a precise scientific basis and a careful planning of the work and verification tools. In this regard, the evaluation tests are to be considered as fundamental tools that allow the adjustments and adaptations of the programming to the responses and emerging issues. Each player or athlete must have a personal card where, starting from the anthropometric data and the physical-sports history, the results of specific evaluation tests of the various physical and motor skills are recorded at the beginning of the work and verified during the preparation. The evaluation tests must be identified and proposed in a very precise way, corresponding to the characteristics of the various sports activities, the subjects, the equipment and the time available.

\section{CONCLUSIONS}

Modern volleyball, due to the short duration of the game and the increasing intensity of the rhythm, requires much more anaerobic metabolism alactacid, so we increasingly need fast and powerful athletes. The evaluation, training and continuous monitoring of the jump, in relation to technical and tactical aspects and conditional skills, become an important aspect of performance control. With this work I have collected test data from athletes of developmental and not developmental age, analysing the reduction in performance during the transition period. The collection of these data can lead to the right mix of physical preparation and technical aspect, in increasing the athletic abilities of young athletes and in the girls' learning of a methodology and mentality of physical training similar to the advanced team model.

\section{REFERENCES}

Altavilla, G., Mazzeo, F., D'Elia, F., Raiola, G. (2018). Physical commitment and specific work for each role in an elite soccer team, Journal of Physical Education and Sport, 18 (2): 570-574.

Altavilla, G., D'Isanto, T., Di Tore, A.P., Raiola, G. (2018). Free throw and outcomes: Pilot study on intensive training versus extensive one, Journal of Human Sport and Exercise, 13 (3): 494-503. https://doi.org/10.14198//hse.2018.133.02

Altavilla, G., D'Isanto, T., \& Di Tore, P. (2018). Anthropometrics characteristics and jumping ability in basketball. Journal of Human Sport and Exercise, 13(2proc), S385-S392. https://doi.org/10.14198/ihse.2018.13.Proc2.22

Altavilla, G., Di Tore, P.A., Riela, L., D'Isanto, T. (2017). Anthropometric, physiological and performance aspects that differentiate male athletes from females and practical consequences, Journal of Physical Education and Sport, 17: 2183-2187.

Cirillo, G., Nughes, E., Acanfora, A., Altavilla, G., D'Isanto, T. (2016). Physical and port education testing by quantitative and qualitative tools in assessment in senior school: A proposal. Sport Science, 9: 97-101.

Dr.Lobietti R., PhD, Numero di salti in gara: confronto tra ruoli e posizioni. https://www.federvolley.it/sites/default/files/news/allegat/957.pdf

D'Elia, F., Mazzeo, F., Raiola, G. (2018). The core curriculum in the university training of the teacher of physical education in Italy, Journal of Human Sport and Exercise, 13(Proc2): S413-S420. https://doi.org/10.14198/jhse.2018.13.Proc2.25

D'Isanto, T., Di Tore, P. \& Altavilla, G. (2018). Correlation of the anthropometric characteristics and the ability to jump in volleyball. Journal of Human Sport and Exercise, 13(2proc), S393-S400. https://doi.org/10.14198/ihse.2018.13.Proc2.23

Di Tore, A.P., Raiola, G., D'Isanto, T. (2018). Situation awareness in sports science: Beyond the cognitive paradigm, Sport Science, 11 (1): 44-48. 
Di Tore, P.A., Raiola, G. (2012). Case study on physical education and sport in Naples, Italy, Mediterranean Journal of Social Sciences, $3(11)$ : 471-476.

Gaetano, R. (2012). Motor learning and didactics into physical education and sport documents in middle school-first cycle of education in Italy, Journal of Physical Education and Sport, 12 (2): 157-163.

Gaetano, R. (2012). Didactics of volleyball into the educate program for coaches/trainers/technicians of Italian Federation of Volleyball (FIPAV). Journal of Physical Education and Sport, 12 (1): 25-29.

Gaetano, A. (2016). Relationship between physical inactivity and effects on individual health status, Journal of Physical Education and Sport, 16: 1069-1074.

Forte D., Altavilla G., (2018). Preliminary correlation between anthropometric and performance data in volleyball about the transition period, Journal of Physical Education and Sport, 18:1994-1998.

Raiola, G., D'Elia, F., \& Altavilla, G. (2018). Physical activity and sports sciences between European research council and academic disciplines in Italy. Journal of Human Sport and Exercise, 13(2proc), S283-S295. https://doi.org/10.14198//hse.2018.13.Proc2.13

Raiola, G. (2017). Motor learning and teaching method, Journal of Physical Education and Sport, 17: 2239-2243.

Raiola, G., Di Tore, P.A. (2017). Motor learning in sports science: Different theoretical frameworks for different teaching methods, Sport Science, 10: 50-56.

Raiola, G., D'isanto, T. (2016). Assessment of periodization training in soccer. Journal of Human Sport and Exercise, 11: 267-278. https://doi.org/10.14198/jhse.2016.11.Proc1.19

Raiola, G. (2014). Teaching method in young female team of volleyball, Journal of Physical Education and Sport, 14 (1): 74-78.

Raiola, G. (2014). Motor control and learning skills according to cognitive and ecological dynamic approach in a vision on behaviorism, cognitive, Gestalt and phenomenology theories, Mediterranean Journal of Social Sciences, 5 (15): 504-506. https://doi.org/10.5901/mjss.2014.v5n15p504

Raiola, G. (2013). Body knowledge and motor skills, Knowledge Cultures, 1 (6): 64-72.

Raiola, G., Di Tore, P.A. (2012). Statistical study on bodily communication skills in volleyball to improve teaching methods, Journal of Human Sport and Exercise, 7 (2): 468-488. https://doi.org/10.4100/jhse.2012.72.12

Raiola, G., Di Tore, P.A. (2012). Bodily communication skills and its incidence on female volleyball championship to enhance didactics, Journal of Human Sport and Exercise, 7 (2): 365-375. https://doi.org/10.4100/ihse.2012.72.03

Raiola, G., Di Tore, A. (2012). Non-verbal communication and volleyball: A new way to approach the phenomenon, Mediterranean Journal of Social Sciences, 3 (2): 347-356. https://doi.org/10.5901/mjss.2012.v3n2.347

Raiola, G. (2012). Bodily communication in volleyball between human and experimental sciences, Mediterranean Journal of Social Sciences, 3 (1): 587-597.

Tiziana, D., Antonetta, M., Gaetano, A. (2017). Health and physical activity, Sport Science, 10 (1): 100 105.

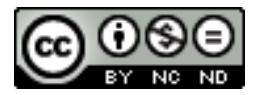

This work is licensed under a Attribution-NonCommercial-NoDerivatives 4.0 International (CC BY-NC-ND 4.0). 